\title{
A CATEGORIA DETERMINANTE NA AQUISIÇÃOO DO PORTUGUÊS L2 POR SURDOS
}

\author{
Fani Costa de ABREU (D) \\ Secretaria de Estado de Educação do Distrito Federal (SEEDF) \\ Heloisa Maria Moreira Lima SALLES (DD \\ Universidade de Brasília (UnB)
}

\section{○}

OPEN ACCESS

EDITADO POR

- Miguel Oliveira, Jr. (UFAL)

- René Almeida (UFS)

REVISADO POR

- Jair Barbosa (UFAL)

- Maria da Cunha Pereira (PUC-SP)

SOBRE OS AUTORES

- Fani Costa de Abreu

Conceptualização, Curadoria de

Dados, Investigação, Metodologia,

Recursos, Escrita - Rascunho

Original e Escrita - Análise e Edição.

- Heloisa Maria Moreira Lima Salles

Análise Formal, Metodologia,

Administração do Projeto, Supervisão

e Escrita - Análise e Edição.

\section{DATAS}

- Recebido: 29/01/2020

- Aceito: 16/06/2020

- Publicado: 20/12/2020

\section{COMO CITAR}

ABREU, Fani C.; SALLES, Heloisa M. M. L. (2020). A categoria determinante na aquisição do Português L2 por surdos. Cadernos de Linguística, v. 1, n. 2, p. 01 17.

\section{RESUMO}

O estudo investiga o uso da categoria determinante na estrutura gramatical da interlíngua de surdos aprendizes de português brasileiro (PB) escrito como segunda língua. Adotando os pressupostos teóricos da gramática gerativa, assumimos a hipótese de que a Língua de Sinais Brasileira (LSB) lexicaliza a categoria determinante (D) pela apontação, que codifica a referência dos nomes, assim como o sistema de pronomes pessoais e demonstrativos. Os dados da interlíngua foram produzidos por 11 participantes surdos, falantes de LSB como L1, em atividade semiestruturada de produção escrita em português, tendo como referência sentenças produzidas na LSB. Os participantes foram distribuídos nos níveis básico (G1) e intermediário (G2), de acordo com a proficiência no PB. Verificou-se a presença de desenvolvimento linguístico, uma vez que, na comparação entre $\mathrm{G} 1$ e $\mathrm{G} 2$, existe redução do padrão estrutural em que o determinante está ausente (nominal nu). Em relação ao uso do determinante, observa-se maior taxa de uso do pronome demonstrativo do que do artigo definido. Esse resultado é analisado como interferência da L1, pela presença do traço dêictico no núcleo D na LSB. 


\section{ABSTRACT}

This study investigates the use of determiners in the interlanguage of deafs learning (written) Brazilian Portuguese (BP) as a second language (L2). Adopting the theoretical assumptions of the generative grammar, we assume the hypothesis that the Brazilian Sign Language (BSL) lexicalizes the determiner category (D) by means of a pointing sign, which encodes the reference of the noun, as well as the system of personal and demonstrative pronouns. The data of the interlanguage were provided by 11 deaf participants having the Brazilian Sign Language (BSL) as their first language (L1). They were enrolled in a semi-structured activity of language production in (written) Portuguese, having sentences in BSL as a reference. The participants were distributed in two groups, according to their level of proficiency in BP: G1 (basic) e G2 (intermediary). A relevant result is the presence of language development, as $\mathrm{G} 2$ displays a significant reduction in the use bare nouns (in which the determiner is absent). Regarding the use of the determiner, a higher rate in the use of the demonstrative pronoun was observed as compared to the definite article. This result is analised as L1 interference, given the presence of the 'deictic' feature on the $\mathrm{D}$ head in BSL.

PALAVRAS-CHAVE

Aquisição de Segunda Língua; Determinantes; Interlíngua; Deixis.

\section{KEYWORDS}

Second Language Acquisition; Determiners; Interlanguage; Deixis. 


\section{INTRODUÇÃO}

Chomsky (1971) afirma que o sistema de conhecimento e crenças do ser humano é resultante de uma relação mútua de mecanismos inatos, processos de maturação determinados geneticamente e interação com o meio físico e social. De acordo com o autor, o estudo do sistema linguístico tem contribuído para evidenciar a natureza do conhecimento humano, uma vez que "não há qualquer padrão externo que permita verificar o sistema de regras e princípios relacionando som e significado - a gramática - construídos pela mente" (CHOMSKY, 2008, p.39). A investigação parte da observação de que um falante conhece sua língua perfeitamente, não havendo necessidade de aprendizado, o que revela que é possível distanciar o estudo da linguagem de questões empíricas. Sobre o conhecimento linguístico, o autor recorre à invariabilidade das propriedades das línguas em relação à forma como esse conhecimento é adquirido (apesar da diversidade), o que o leva a concluir sobre a existência de um esquematismo, definido como "uma faculdade da linguagem inata, que é, por sua vez, um componente da estrutura da mente" (CHOMSKY, 2008, p.69). Assim, é postulado o conceito de Gramática Universal (GU), que se refere ao sistema de propriedades do estado mental inicial da criança que está adquirindo uma língua.

Este trabalho se desenvolve no âmbito da teoria gerativa, tomando a língua (interna) como o objeto da pesquisa para investigar a aquisição da categoria determinante no português (escrito) como segunda língua por surdos falantes da Língua de Sinais Brasileira' como primeira língua. Assume-se, portanto, que a faculdade da linguagem constitui uma dotação biológica da espécie humana, cujo arcabouço se mantém estável, independentemente da condição perceptual das pessoas. Nesse sentido, assim como as pessoas ouvintes, pessoas surdas (ou surdas cegas) são habilitadas ao desenvolvimento de uma língua, desde que expostas ao input linguístico adequado - a língua oral (oral-auditiva), a língua de sinais (visual-espacial ou táctil). Essa conclusão tem como corolário o entendimento de que as línguas de sinais (LS) observam as mesmas restrições que se aplicam às línguas orais (LO) (STOKOE et al., 1976; BELLUGI e KLIMA, 1972; SIPLE, 1978 apud QUADROS, 2011). Isto é, a LS apresenta todos os níveis linguísticos de uma LO: fonológico, sintático e semântico. No Brasil, a LSB começou a ser investigada nas décadas de 1980 e 1990, e especificamente na década de 90 iniciaram os estudos sobre a aquisição da linguagem em crianças surdas. As investigações mostram que surdos filhos de pais surdos adquirem a gramática da LS do mesmo modo que as crianças ouvintes.

1 LSB é a sigla para Língua de Sinais Brasileira. Além dessa forma de designação, é encontrada também a de Língua Brasileira de Sinais - Libras (referida dessa forma na Lei $n^{\circ} 10.436$, de 24 de abril de 2002). Escolhemos a primeira designação, e a respectiva sigla (LSB), por ser a que segue os padrões internacionais de denominação das línguas de sinais. 
Petitto (1987 apud QUADROS, 1997) apresenta os estágios de aquisição da LS de crianças surdas, do balbucio ao estágio das múltiplas combinações, mostrando a equivalência com a aquisição da LO. No entanto, sabe-se que as crianças surdas estão expostas a diferentes cenários de aquisição de língua, devido ao contexto em que se encontram: há crianças surdas filhas de pais surdos, mas há crianças surdas filhas de pais ouvintes, há pais ouvintes que não utilizam língua de sinais e os que a utilizam; e ainda há ambientes de aquisição da língua de sinais em instituições como escolas, igrejas, associações de surdos. $\mathrm{O}$ desenvolvimento da linguagem vai depender, portanto, do ambiente linguístico e do período em que se detectou ou se instaurou a surdez. Quanto mais rápido o acesso à LS pela criança surda, menores serão as perdas e as possíveis lacunas no processo. Tão logo a pessoa surda se torna proficiente na própria língua (de modalidade visual espacial), a comunicação, a troca de experiências e o acúmulo de conhecimento se darão de forma natural e espontânea (QUADROS, 2011).

Além da aquisição da primeira língua (L1), a criança surda, dependendo do lugar e das pessoas de convívio, também acaba por adquirir a língua oral dos ouvintes que a cercam, como segunda língua (L2) - nesse caso, o acesso ao input pode ser pela oralização ou por meio da língua escrita. ${ }^{2}$ Em casa, na escola, em ambientes clínicos, a criança está exposta à língua majoritária, que é a língua da sociedade ouvinte; e, portanto, desde a primeira infância, ela passa a ter de dar conta de duas línguas, tornando-se rapidamente um falante bilíngue, dado o contexto em questão. ${ }^{3}$ Dessa forma, a LSB, deve ser a primeira língua da criança surda brasileira e a língua portuguesa a segunda língua. Relaciona-se tal observação ao processo de aquisição dessas línguas pela pessoa surda e definida por sua condição perceptual, a surdez (QUADROS, 1997). Este trabalho, em consonância com a legislação em vigor ${ }^{4}$ e com o entendimento linguístico bilíngue pertinente, toma por referência o desenvolvimento da língua portuguesa como a segunda língua (L2) pelo surdo na modalidade escrita.

2 Neste ponto, não nos posicionamos quanto à adequação da oralização, por meio do método referido como 'oralismo'. Apenas constatamos a existência de surdos oralizados, o que pode ocorrer tanto no contexto de exposição sistemática ao método citado, como informalmente, pela convivência familiar.

3 Em relação ao conceito de bilinguismo, seguimos observação de Silva et al. (2011), segundo a qual a noção de proficiência deve ser avaliada pelo ponto de vista do bilinguismo social, em que se consideram fatores psicossociais no desenvolvimento da L2, distinguindo-se, portanto, das condições em que ocorre a aquisição da L1. Nesse sentido, considera-se que tal conceito é adequado à situação linguística dos surdos.

4 A legislação em vigor refere-se primordialmente à Lei n 10.436 , de 24 de abril de 2002 - conhecida como Lei de Libras -, na qual a Língua Brasileira de Sinais é reconhecida como meio legal de comunicação e expressão dos surdos, como se depreende do Parágrafo Único: Entende-se como Língua Brasileira de Sinais - Libras a forma de comunicação e expressão, em que o sistema lingüístico de natureza visual-motora, com estrutura gramatical própria, constituem um sistema lingüístico de transmissão de idéias e fatos, oriundos de comunidades de pessoas surdas do Brasil. Além da Lei de Libras, consta também a Lei de Acessibilidade, Lei $n^{\circ}$ 10.098, de 19 de dezembro de 2000 . 
O contexto da educação dos surdos, especificamente o ensino-aprendizagem da língua portuguesa como L2, passou por uma trajetória histórica intrincada. Como consequência de uma abordagem oralista para a aquisição do português falado e escrito, sendo o uso da língua de sinais restringido e até mesmo proibido, gerações de surdos sofreram prejuízos linguísticos profundos, além de danos psicossociais. Com a Lei n¹0.436 de 24 de abril de 2002, Lei de Libras, e o Decreto $n^{\circ} 5626$ de 22 de dezembro de 2005, que a regulamenta, veio o reconhecimento da Língua Brasileira de Sinais como a língua oficial da comunidade surda, juntamente com a garantia dos direitos linguísticos dos surdos, entre os quais se destaca a possibilidade de aprender a língua portuguesa como L2 (na modalidade escrita), em instituições públicas de ensino desde a educação infantil.

Se, por um lado, a educação bilíngue para os surdos promove o desenvolvimento cognitivo de crianças que se comunicam em LSB, por outro, nota-se que o ensino da língua portuguesa na modalidade escrita para os surdos, hoje entendida como segunda língua, ainda percorre um acidentado trajeto, carregado de especificidades. Na conjuntura atual, o indivíduo surdo é uma minoria linguística que passa longo período de escolarização em contato com a modalidade escrita da língua majoritária; mas, ao final desse processo, a qualidade da produção escrita da maioria dos jovens surdos aprendizes na língua portuguesa está aquém do desejável - o que corresponde a (pelo menos) 12 anos de acesso ao ensino formal de português como L2. Ressalta-se que não se espera do surdo o desempenho linguístico do falante nativo, mas que possa fazer uso funcional ${ }^{5}$ da modalidade escrita do português nas variadas situações demandadas pela sociedade em que está inserido.

Nesse sentido, a educação de surdos tem apontado como propícia ao perfil perceptual dessas pessoas a abordagem bilíngue. "O bilinguismo é uma proposta de ensino usada por escolas que se propõem tornar acessíveis à criança duas línguas no contexto escolar" (QUADROS, 1997, p. 27). Essa proposta tem sido aceita pelo fato de considerar a LSB como a língua natural dos surdos. Além disso, na presente análise, a língua é entendida como estado mental e atributo inato. Em seu estado inicial, sedia os princípios universais das línguas, assim como as opções de variação, denominadas parâmetros, a serem fixadas na aquisição. Nesse sentido, a LSB, como as demais línguas, é manifestação desse sistema mental, a faculdade de linguagem (FL). Essas propriedades estão formuladas no modelo teórico de Princípios e Parâmetros (CHOMSKY, 1986), e correspondem à competência linguística do falante. Como tal, é o instrumento que viabiliza ao falante/sinalizante perceber, sentir, experimentar, produzir, ampliar sua visão de mundo, encontrar-se com a própria cultura e com a comunidade surda, como qualquer outra criança ouvinte, nas múltiplas

50 uso funcional da língua refere-se às condições que determinam o uso da língua escrita. No caso, usos vinculados aos contextos formais, destacando-se o contexto educacional. Agradeço ao parecerista por indicar a necessidade de esclarecer essa questão, de suma importância na discussão acerca da situação linguística do surdo. 
situações de uso da língua, que correspondem ao desempenho do falante. Conclui-se que é por meio da língua natural que se dão as relações interpessoais e não pela imposição de uma língua oral, incompatível com as demandas perceptuais da pessoa surda.

Dessa forma, o português como segunda língua na modalidade escrita é considerado um enfoque adequado. No entanto, o letramento é sempre foco de preocupação quando se trata de alunos surdos. As estratégias e os métodos para a construção da leitura e da escrita são questionáveis, pois ao deixar a base oral e assumir a língua de sinais (L1) como base para o letramento, o professor de português na modalidade escrita (L2) encontra um ambiente incômodo e, na maioria dos casos, desconhecido. O desenvolvimento da escrita pelo surdo não tem relação direta com a oralidade, cabendo ao professor reconhecer que "se trata da aquisição de uma língua que utiliza um canal perceptual diferente daquele utilizado na língua materna do aprendiz" (SALLES, 2007). Svartholm (1998, apudSALLES et al., 2007) afirma que o professor da língua oral como segunda língua deve tornar o input linguístico acessível e ao máximo disponível, trabalhando os textos com foco na forma e no significado. Esse desafio se torna complexo se o professor não tem acesso à língua de sinais. Salles et al. (2007) observam que o acesso inadequado ao input linguístico prejudica o desenvolvimento da L2 (na modalidade escrita) pelos surdos, com características recorrentes, observáveis de forma sistemática em vários estudos: textos curtos, vocabulário reduzido, ausência de preposições, conjunções e artigos, falta de concordância verbal e nominal, ordem dos termos da oração aparentemente aleatória, estrutura textual com pouca complexidade gramatical.

O fato é que o texto dos surdos evidencia um processo de aquisição de segunda língua (ASL) e fases de aquisição, o que, na escrita, é identificado pelo surgimento de uma gramática de interlíngua. O linguista Larry Selinker (1972, apud PAIVA, 2014) é o proponente do conceito de interlíngua, presente originalmente no trabalho de Pit Corder (1967), do qual Selinker era discípulo. Corder traz o conceito de que os erros são ausência de conhecimento, logo são evidências de um sistema linguístico que se caracteriza por níveis de desenvolvimento de uma L2. Dessa forma, "postula a existência de uma gramática mental própria do aprendiz, pois os erros seguem padrões e não se dão de forma aleatória. As interlínguas são marcadas por variação e em alto grau de sistematicidade" (PAIVA, 2014, p. 160). Logo, o conceito de interlíngua (IL) refere-se a um estágio de desenvolvimento da $L 2$ em que o falante se utiliza de um sistema linguístico que não é nem o seu nativo, nem o da língua que está sendo adquirida, pois exibe traços dos dois sistemas e/ou de nenhum dos dois. Miccoli (2013, apudPAIVA, 2014) observa que o modelo de interlíngua atribui papel importante à língua materna, reforçando o acesso indireto à GU. No entanto, Selinker (1972 apudPAIVA, 2014) refina essa ideia, definindo interlíngua como gramática temporária, que pode ser permeada por regras preexistentes ou mesmo criada pelo aprendiz de segunda língua. Sobre a origem e natureza do conhecimento linguístico de L2, algumas hipóteses 
são consideradas por White (2003), mas uma delas é a do acesso indireto ou parcial à GU, em que a Gramática Universal restringe a aquisição da L2. No processo de aquisição da L2, assumimos a hipótese de que a L1 intervém no processo que conduz à apropriação dos valores paramétricos da língua alvo pelo aprendiz (o que não implica a convergência completa em relação à língua alvo). Essa intervenção é referida como interferência positiva, se houver convergência entre a L1 e a L2, em relação a uma dada propriedade morfossintática, ou negativa, caso haja divergência (ELLIS, 1997).

Observados esses princípios, o presente trabalho tem por objetivo analisar a estrutura gramatical da interlíngua de surdos aprendizes de português (L2) na modalidade escrita quanto à aquisição dos determinantes, considerando os níveis de proficiência e as fases da interlíngua (ver nota 10). Na próxima seção, apresentaremos os pressupostos teóricos em relação às propriedades formais da categoria dos determinantes, bem como a evidência da ocorrência dessa categoria na LSB. Na seção 3, observaremos os padrões estruturais encontrados nos dados da interlíngua. Por fim, traremos a discussão dos padrões à luz dos fundamentos teóricos propostos inicialmente.

\section{A CATEGORIA DETERMINANTE: PRESSUPOSTOS TEÓRICOS}

Ao abordar a categoria dos determinantes, é preciso considerar as propriedades morfossintáticas e semânticas, o que significa entender as noções de referencialidade e definitude, e ainda observar as relações argumentais do predicado, por um lado, e as propriedades morfossintáticas, por outro.

Antes da formulação da teoria X-barra, o determinante era analisado como uma categoria que ocupava a posição de especificador (Spec) do sintagma nominal (nominal phrase/NP), com uma função de atribuir definitude. Além disso, a posição de Spec na estrutura do NP poderia alojar núcleos (projeção mínima) e sintagmas (projeção máxima). No entanto, no modelo teórico da regência e ligação (Government and Binding theory/GB), Chomsky (1986) propõe que a posição do especificador seja ocupada somente por categorias de nível máximo, o que inviabiliza a realização uniforme dos determinantes nessa posição, pela diversidade das categorias envolvidas.

Posteriormente, Abney (1987 apud MACEDO-COSTA, 2016) propõe analisar o determinante (D) como uma categoria funcional, que projeta seu nível máximo, o sintagma determinante (DP), e seleciona o sintagma nominal (NP). Essa abordagem é referida como hipótese do DP, fazendo-se assim um paralelo entre o NP e o VP, já que este último é selecionado por uma categoria funcional, no caso, o sintagma flexão (inflectional phrase/P). 
Empiricamente, considerou línguas como o turco, em que ocorre a concordância do nome (possuído) com o nome que designa o possuidor na projeção estendida do sintagma nominal. A proposta de que o determinante é realizado como uma projeção máxima na estrutura do sintagma nominal também é defendida por Longobardi (1994 apud MACEDO-COSTA, 2016). Para esse autor, mesmo se o determinante não é morfologicamente realizado, a projeção funcional está na estrutura, uma vez que as línguas que não possuem artigo codificam a referencialidade, a unicidade, a definitude, a especificidade, por meio de traços formais que estão vinculados a posições sintáticas específicas.

Os determinantes não são representados apenas por artigos, apesar de artigos constituírem a categoria determinante. Na estrutura do determinante, podem ser encontradas outras classes de palavras, que têm essa função designativa e precedem um nome, como, por exemplo, pronomes demonstrativos e possessivos. Brito (2003) observa que os determinantes restringem o núcleo nominal e, a partir do nome, criam uma expressão referencial. A autora distingue os determinantes não dêiticos - artigos definidos e indefinidos -, e dêiticos - pronomes possessivos e demonstrativos. No português brasileiro (PB), como determinantes, são encontrados, além dos artigos, os pronomes possessivos, os pronomes demonstrativos, as expressões quantificadoras e os numerais.

Assim como nas línguas orais, a categoria dos determinantes é evidenciada na LSB. Ferreira-Brito (1995) apresenta essa evidência mostrando que a referenciação por meio da apontação é capaz de trazer descrição definida. Além disso, na LSB, a marcação da dêixis (distal e proximal) permite referir ou co-referir. A autora explica que assim como em línguas orais, é possível utilizar pronomes pessoais, demonstrativos e possessivos, mas a posição do corpo ou olhadelas também podem realizar tais propriedades. Como exemplo, tem-se os sinais de apontação para pontos no espaço, referenciando pessoas ou objetos fixados pelo falante, presentes ou não.

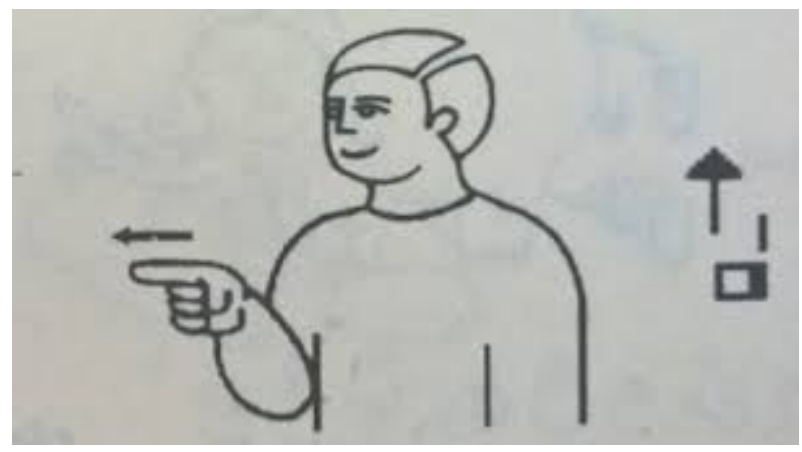

Figura 1.

Fonte: CAPOVILLA; RAPHAEL; MAURÍCIO (2013).

Considerando a ocorrência dos dêicticos referenciadores na LSB, Prado e Lessa-deOliveira (2012) e Prado (2014) propõem que a apontação pode ser identificada como 
elemento da categoria dos determinantes (D). As autoras denominam o sinal de apontação por meio do rótulo Localizador (Loc). Argumentam também que, na gramática de LSB, os Locs são eminentemente dêiticos, dividindo-se em dois grupos: Locs articulados (LocA), pela presença de MLMov (mão/locação/movimento) e Locs não-articulados (LocNA), em que MLMov estão ausentes, sendo realizados apenas com a utilização da direção do olhar (do) e do movimento do corpo (mc). Para as autoras, tanto LocA como LocNA são determinantes que realizam o núcleo $\mathrm{D}$, podendo ocorrer antepostos ou pospostos ao nome. Seguindo a geometria de traços da categoria D proposta por Carvalho (2008) para o português (com base em HARLEY \& RITTER (2002), BÉJAR (2003), citados pelo autor), Prado (2014, p. 88) postula a mesma estrutura de traços formais para o núcleo D em LSB, conforme representada a seguir.

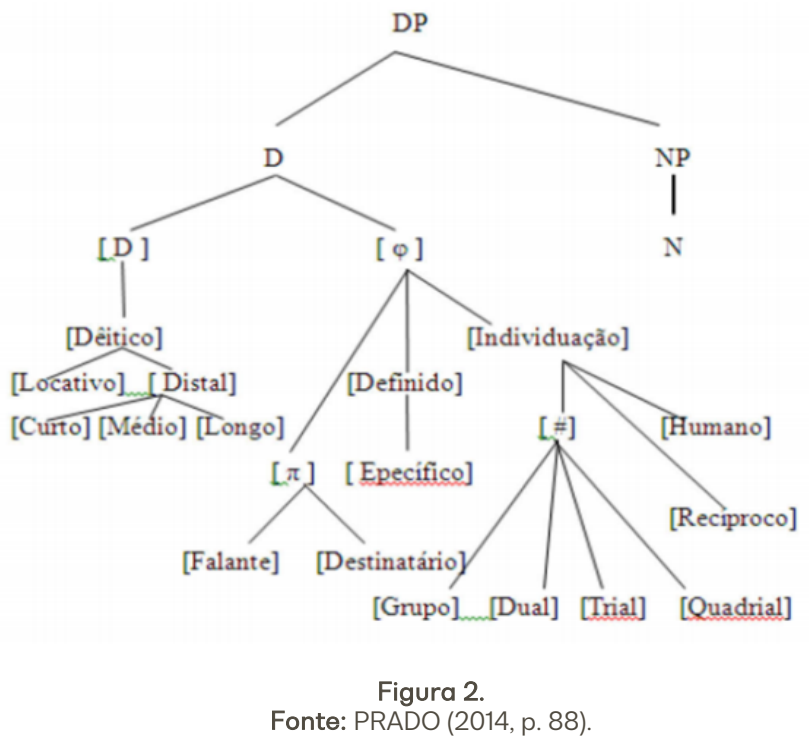

De acordo com Prado (2014, p. 89), no modelo de Carvalho (2008), o traço D codifica informações a respeito do nome e o identificam como um argumento, pela codificação dos traços [DEFINIDO] e [ESPECÍFICO]. A autora acrescenta que, tendo em vista a importância da apontação para a referenciação nas línguas de sinais, é adequado propor a separação entre o traço $D$ e o nó $[\varphi$ ], responsáveis respectivamente pelo traço [DÊITICO], que torna a checagem da raiz [D] obrigatória, e pelos traços de pessoa, gênero e número, codificados pelo nó $[\varphi]$. Na geometria de $[\varphi]$, a autora propõe retirar o nó [PARTICIPANTE], originalmente proposto por Carvalho (2008), deixando apenas o nó pessoa [ா], sob a alegação de que a distinção entre [FALANTE] e [DESTINATÁRIO] capta o contraste entre a $1^{\text {a }}$ e a $2^{a}$ pessoa, por um lado (especificadas como participantes do discurso), em oposição à $3^{a}$ pessoa, definida como não-pessoa, nos termos de Benveniste (1976). No nó [INDIVIDUAÇÃO], são incluídos os traços referentes à quantificação, a saber [GRUPO], [DUAL], [TRIAL], [QUADRIAL], e os traços [HUMANO] E [RECÍPROCO], por serem lexicalizados na LSB. Observa ainda que os 
traços [DEFINIDO] e [ESPECÍFICO] são separados do nó pessoa [ח], pelo fato de haver Locs que codificam esses traços, mas não codificam o traço de pessoa. Finalmente, afirma que o traço [ESPECÍFICO] é colocado como subespecificação de [D], por sua propriedade de referenciação, e o traço [DEFINIDO] como subespecificação de [INDIVIDUAÇÃO], em face das propriedades discursivas desse traço.

Os dados a seguir, extraídos de Prado (2014), ilustram possibilidades de arranjos dos traços 6 :

a. O Loc anteposto - [D [DÊITICO] [ESPECÍFICO]] e [ $\varphi$ [INDIVIDUAÇÃO[DEFINIDO]] checa o núcleo D:

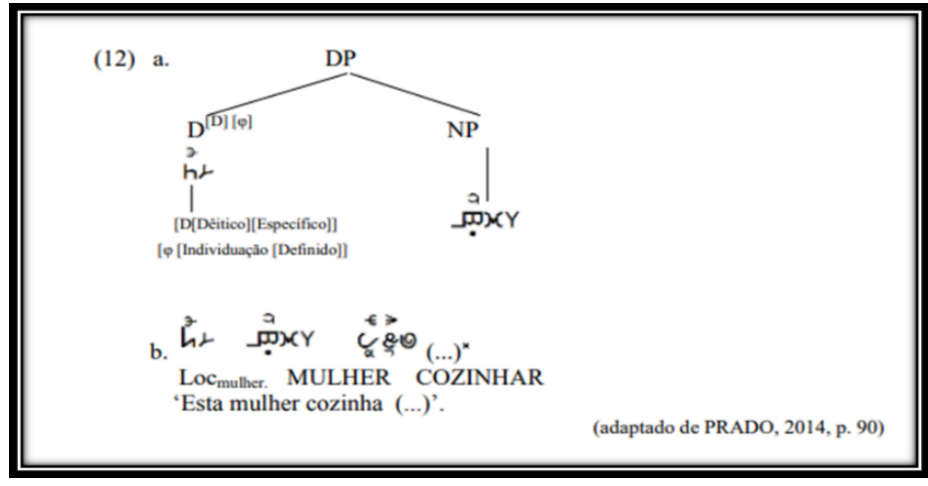

Figura 3.

Fonte: PRADO (2014, p. 90)

b. O Loc (posposto) possui apenas o traço [[ $\varphi[$ [INDIVIDUAÇÃO [DEFINIDO]] e licencia somente o traço $[\varphi]$, ficando o traço [D] para ser checado pelo $N$ (mulher), que se adjunge a D para realizar essa operação de concordância:

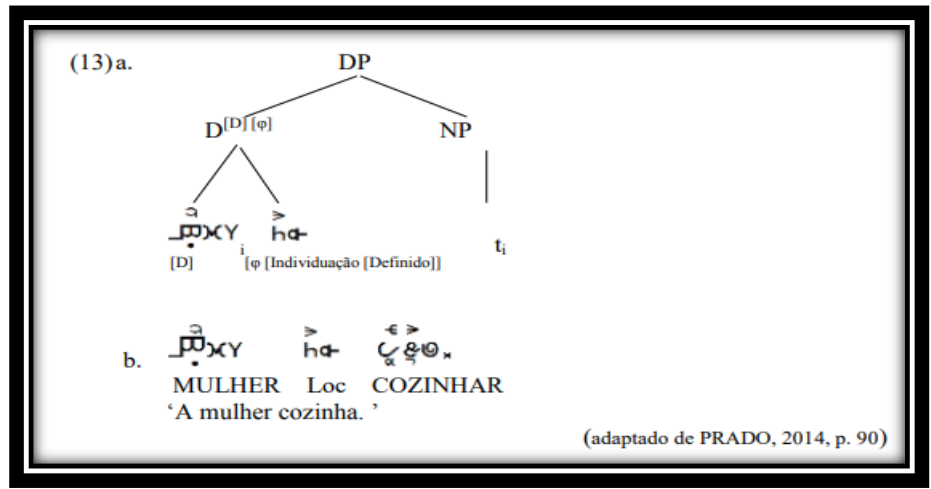

Figura 4.

Fonte: PRADO (2014, p .90).

6 Os exemplos são apresentados pelo sistema de transcrição em que o significado do sinal é representado pela palavra correspondente em português, grafada em letra maiúscula. Acompanham ainda o registro no Sistema de Escrita para Língua de Sinais (SEL). Para informações sobre a escrita SEL, consultar o Blog Escrita SEL em: http://sel-libras.blogspot.com.br/ 
c. A ausência do Loc faz com que recaia no nominal HOMEM a checagem dos traços [D] e $[\varphi]$, por meio do movimento de $N$ para $D$, o que resulta na interpretação genérica desse nome:

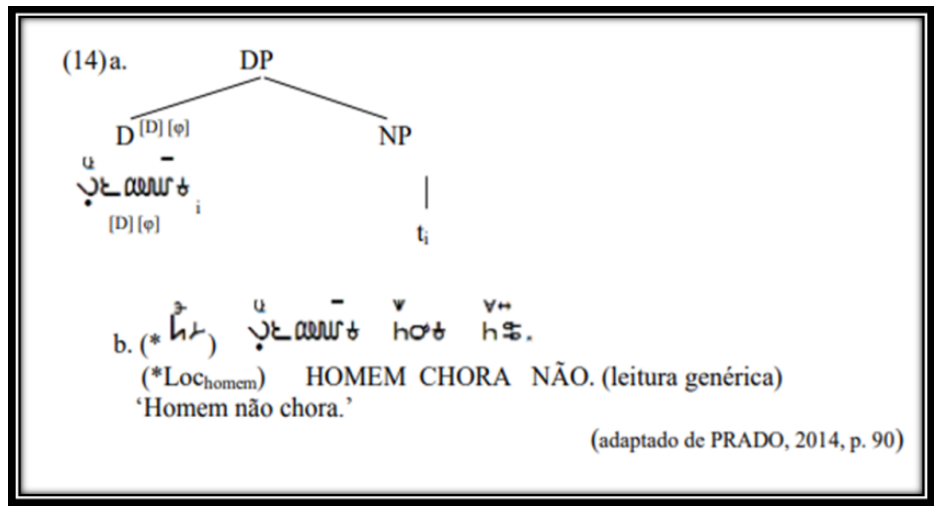

Figura 5

Fonte: PRADO (2014, p. 90)

\section{O ESTUDO EXPERIMENTAL: METODOLOGIA E RESULTADOS}

Conforme mencionado, o presente estudo tem por objetivo investigar a interlíngua de surdos aprendizes de português (escrito) como L2, considerando, particularmente, a ocorrência dos determinantes na estrutura do sintagma nominal. Para tanto, constituímos um corpus com dados de produção escrita, em que a categoria dos determinantes do português é eliciada por meio de atividade semi-estruturada. O estudo adotou análise quantitativa, verificando a frequência da variável 'presença da categoria determinante', bem como a análise qualitativa dos resultados.

a) Dos participantes

A atividade contou com 11 participantes, assim distribuídos: surdez congênita: 36,36\%; surdez adquirida na infância: 54,54\% e Não Sabe/Não Respondeu: 9,09\%. Em relação ao grau de surdez, verificou-se o seguinte: profunda: $81,8 \%$; leve (ouço um pouco a voz das pessoas): $18,2 \%$. A idade dos participantes varia entre 20 e 45 anos de idade. A aquisição da L1 ocorreu nas seguintes fases: infância: 72,72\%; adolescência: 9,09\%; fase adulta: 9,09\%. Os participantes foram divididos em dois grupos por nível de proficiência do português escrito: básico e intermediário ${ }^{7}$. A distribuição dos participantes por nível

7 O Quadro Europeu Comum de Referência (QECR) para as línguas foi utilizado como um instrumento norteador para o nivelamento dos participantes. Foi considerada apenas a representação global e simplificada apresentada no QECR (p. 48), em que são apresentadas referências em uma escala global, divididas e subdivididas em: utilizador elementar (A1 e A2), utilizador independente (B1 e B2) e utilizador proficiente (C1 e C2). Neste trabalho, nomeamos o nível do utilizador elementar como nível básico e o nível do utilizador independente como nível intermediário. Não observamos participantes no nível de utilizadores proficientes pelo fato de não haver, no momento da pesquisa, 
de proficiência foi a seguinte: Grupo 1- nível básico: 6 participantes. Grupo 2 - nível intermediário: 5 participantes.

\section{b) Dos procedimentos}

O pesquisador deslocou-se com os participantes até um supermercado, onde apresentou um conjunto de sentenças que descreviam situações contextualizadas. No total, cada grupo foi submetido a 17 sentenças em LSB. Após cada sentença, os participantes deveriam escrever a sentença correspondente em português. Todas as sentenças sinalizadas utilizaram a apontação (Localizador articulado/LocA), para realizar a referenciação, e os objetos referenciados estavam presentes (contextualizados).

\section{c) Da amostra}

Foram produzidas 187 sentenças escritas, a partir das quais foram gerados 115 dados pelo grupo 1 e 95 dados pelo grupo 2 .

\section{d) Dos dados}

Os padrões de estruturação do DP evidenciados na interlíngua foram os seguintes, com a respectiva exemplificação (incluindo-se a sentença em LSB vinculada):

(i) [Det $+\mathrm{N}]$ - Uso de determinante (este, esse, aquele, lá e trial) anteposto ao nome

(1) Essas árvores são altos

Locárvore ÁRVORESALTAS

(2) Três salas estão fechado

SALA LOC trial FECHADAS

(ii) $[\varnothing+N]$ - Ausência de determinantes anteposto ao N (nome nu).

(3) Árvore está muito alto

LoCárvore ÁRVORESALTAS

(iii) [Art + N] - Presença do determinante artigo anteposto ao nome.

(4) Os cerveja está geladeira dentro frio

Loc $_{\text {cerveja }}$ GELADEIRA FRIA...

(iv) $[\mathrm{IX}+\mathrm{N}]$ - Presença de pronome de $3^{\mathrm{a}}$ pessoa anteposto ao nome

(5) Eles flores acho bonita

Locflores FLOR ACHAR1p BONIT@

(v) [Det + Art + N] - Uso de determinante (qualquer) seguido de artigo definido anteposto ao nome.

(6) Aqueles os pães são delícias

Loc pães PÃESDELÍCIA

(vi) [Det $+\varnothing]$ - Uso de determinante e ausência do nome.

(7) Esta que eu amo, mas esta outra que eu odeio

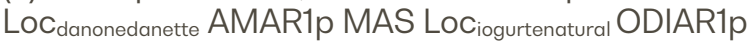

estudantes nesse nível. Os participantes eram estudantes de um curso particular de língua portuguesa como segunda língua para surdos e não foram submetidos a testes de nivelamento. Os níveis de proficiência foram determinados com base na produção de textos escritos realizada em situações prévias, considerando: uso de concordância verbal e nominal, ordem dos termos na oração, emprego de preposição. 
A tabela 1, a seguir, apresenta os dados quantitativos, distribuídos em função dos padrões de estruturação e dos grupos de proficiência.

\begin{tabular}{|c|c|c|c|c|c|c|}
\hline & $\begin{array}{c}\text { (i) } \\
\text { Det + N }\end{array}$ & $\begin{array}{l}\text { (ii) } \\
0+\mathrm{N}\end{array}$ & $\begin{array}{c}\text { (iii) } \\
\text { Art + N }\end{array}$ & $\begin{array}{c}\text { (iv) } \\
\mathrm{IX}_{3}+\mathrm{N}\end{array}$ & $\begin{array}{c}\text { (v) } \\
\text { Det+Art + N }\end{array}$ & $\begin{array}{c}\text { (vi) } \\
\text { Det + }\end{array}$ \\
\hline \multicolumn{7}{|l|}{ GRUPO 1-G1 } \\
\hline *Nível básico & $13 / 115$ & $43 / 115$ & $25 / 115$ & $29 / 115$ & $1 / 115$ & 4/115 \\
\hline $\begin{array}{l}\text { N' do dados tipicos/totaldo } \\
\text { dados observados }\end{array}$ & $11,30 \%$ & $37,39 \%$ & $21,73 \%$ & $25,21 \%$ & $0,86 \%$ & $3,47 \%$ \\
\hline \multicolumn{7}{|l|}{ GRUPO 2 - G2 } \\
\hline *Nível inter. & $43 / 95$ & $7 / 95$ & $31 / 95$ & $0 / 95$ & $6 / 95$ & $8 / 95$ \\
\hline $\begin{array}{l}\text { Nedo dades tipicos/totalde } \\
\text { dasosos obserrados }\end{array}$ & $45,26 \%$ & $7,36 \%$ & $32,63 \%$ & $0 \%$ & $6,31 \%$ & $8,42 \%$ \\
\hline
\end{tabular}

\section{ANÁLISE DOS DADOS E DISCUSSÃO}

O primeiro ponto a destacar é a existência de desenvolvimento linguístico em relação à variável 'presença da categoria determinante', uma vez que, na comparação entre G1 e G2, existe redução significativa do padrão estrutural (ii), que corresponde ao nome nu: de $37,39 \%$ para $7,36 \%$. A hipótese é que $\mathrm{G} 1$ desconhece os itens lexicais que realizam a categoria $D$ em português, o que impossibilita a relação estrutural com a categoria LocA, disponível na L1.

Inversamente, em relação aos padrões estruturais (i) e (iii), o aumento na frequência do uso do determinante no $\mathrm{G} 2$, de $11,3 \%$ para $45,26 \%$, em relação ao uso de demonstrativos, e de $21,73 \%$ para $32,63 \%$, em relação ao uso de artigos, indica desenvolvimento linguístico para o uso do item lexical relevante da língua alvo (não foi considerada a concordância nominal). A hipótese é da interferência positiva da L1 (mediante LocA), em relação ao uso do demonstrativo/ artigo da língua alvo, mediante o acesso ao input linguístico da L2, que propicia o acesso aos itens lexicais relevantes (pronomes demonstrativos e artigos).

Além disso, o alto percentual do padrão (i) em G2 demonstra maior facilidade no desenvolvimento linguístico para o uso dos pronomes demonstrativos. A hipótese é a de que existe interferência positiva da L1, mediante o uso da dêixis (distal e proximal) por meio de (LocA), que referencia e correferencia em LSB (cf. FERREIRA-BRITO, 1995), categoria semântica com orientação para pessoas no discurso (PRADO, 2014, p. 125).

Cabe observar que o padrão estrutural (iii), que corresponde ao uso do artigo, apresenta um aumento menos significativo na frequência, do que em relação ao padrão (i), o 
que demonstra menor interferência (positiva) da categoria Loc. Esse resultado sugere a não correspondência total entre as propriedades de Loc na L1 e da categoria artigo na L2.

O padrão (iv), em que o pronome de $3^{\text {a }}$ pessoa 'ele' ocorre na estrutura do sintagma nominal, sugere que $G 1$ está sob interferência negativa de L1, tendo em vista o uso da referenciação dêitica, por meio da apontação, na codificação de pronomes pessoais em LSB. Essa estrutura não é encontrada no G2, o que aponta para a ocorrência do processo da fixação paramétrica para uso dos determinantes em português, mediante o acesso ao input da L2.

Em relação ao padrão estrutural (v), G2 evidencia maior frequência de uso da estrutura do duplo determinante do que G1, o que não era previsto, embora a frequência seja baixa. A hipótese é que os aprendizes mais proficientes têm mais acesso ao input da língua alvo e mais conhecimento dos itens lexicais da língua alvo, tendo, portanto, mais opções no processo de escolha lexical para definir traços de referencialidade e definitude. Em português, o pronome demonstrativo e o artigo não co-ocorrem, mas em outras línguas é encontrada a estrutura [Det + Art + N] (CARVALHO, 2011). De acordo com Brugè (1996) e Guardiano (2009 apud Carvalho, 2011), na proposta de Abney (1987), demonstrativos e artigos ocupam posições diferentes dentro da estrutura do sintagma determinante. Deve haver, portanto, uma estrutura universal que descreva essas posições. Se for esse o caso, o uso da estrutura [Det + Art + N] por aprendizes de G2 estaria evidenciando acesso direto à GU, uma vez que tal estrutura não é encontrada nem na L1, nem na L2 uma hipótese que deixamos para investigação futura.

O padrão (vi) é uma estrutura que surgiu em sentenças comparativas, o que não era foco da análise, apesar de ser realizada por G2 pelo uso de elipse do nome na segunda oração. Nesse contexto estrutural, fez-se presente o uso de locativos (lá, aqui, outro lugar, ali, outro) ao invés de demonstrativos.

O estudo permitiu confirmar que os participantes estão em processo desenvolvimento linguístico em direção à língua alvo (L2) (assumindo-se a hipótese da Gramática Universal, nos termos de CHOMSKY, 1965;1986; 1999), bem como observar que a gramática da interlíngua manifesta interferência (negativa) da L1 (WHITE, 2003), por exemplo, em relação ao padrão (iv), que corresponde à estrutura com o pronome de $3^{a}$ pessoa 'ele' anteposto ao nome em G1, seguindo-se a refixação de parâmetro, com o desaparecimento desse padrão em G2. Confirma-se também o desenvolvimento linguístico, na relação com os níveis de proficiência, pelo aumento no uso convergente do determinante (artigo ou pronome demonstrativo), em relação à diminuição do uso do nominal nu (configuração (ii)), apesar da aparente heterogeneidade nas características da interlíngua dos participantes, revela interferência (positiva), tendo em vista a correspondência com Loc na estrutura do DP, na LSB (desde que os itens lexicais estejam disponíveis no input linguístico). Tem-se também evidência de opcionalidade, que consiste no "estado de competência gramatical" que 
seleciona variantes linguísticas ao longo da aquisição (SORACE, 1999, 2003, apud SALLES e CHAN-VIANA, 2007), estando sua incidência na estrutura da interlíngua relacionada ao grau de proficiência (ao ponto de se tornar residual). É o que o ocorre, em relação ao uso do nominal nu, em oposição ao uso do determinante, já que manifesta frequência alta no G1 (37,49\%), mas é residual, no G2 (7,36\%).

\section{CONSIDERAÇÕES FINAIS}

Este estudo, desenvolvido no arcabouço teórico gerativista, investigou o uso de determinantes na estrutura do sintagma nominal em dados da produção escrita de surdos aprendizes de português brasileiro como L2, com pelo menos 12 anos de escolarização. Constituímos a análise da interlíngua sob o entendimento de que a categoria dos determinantes está evidenciada na LSB pelo uso da apontação na codificação da dêixis (distal e proximal) e como meio de referenciar e co-referenciar (FERREIRA-BRITO, 1995). Assumimos também os estudos recentes de Prado e Lessa-de-Oliveira (2012) e Prado (2014), que identificam o sinal de apontação, denominado LOC, como núcleo da categoria D, conforme prevê a Hipótese DP, formulada em Abney (1987) e Longobardi (1994).

Partindo-se da hipótese da interferência da L1 na aquisição de português como L2 pelo surdo, os dados revelam que existe desenvolvimento linguístico, uma vez que os participantes do grupo intermediário (G2) manifestam favorecimento para a variável 'presença da categoria determinante', considerada convergente com a língua alvo. Tendo em vista a hipótese de que a categoria Loc, realizada por meio da apontação, lexicaliza o núcleo D na LSB, percebe-se interferência positiva da L1 durante o processo de aquisição. Considerando que os aprendizes mais proficientes são os que tiveram mais acesso ao input da língua alvo (português escrito) durante o período de aquisição, é esperado que os participantes nesse grupo demonstrem maior domínio e mais adequada utilização da categoria dos determinantes da língua alvo. É interessante observar a interferência negativa no grupo menos proficiente, evidenciando uma propriedade paramétrica divergente entre a LSB e o português, que se manifesta pelo uso uniforme da apontação para marcar a categoria referenciadora do nome e da categoria pronominal na LSB, em oposição ao português, que recorre a itens lexicais diferentes para realizar essa marcação. Merece destaque também a ocorrência do duplo determinante no grupo mais proficiente, uma propriedade ausente tanto em LSB quanto no português. Essa situação aponta para a relação entre as estruturas da L1 e o conhecimento mais consistente dos itens lexicais da língua alvo, pelo acesso mais prolongado ao input linguístico. Esse paradoxo sugere que o aprendiz de L2 deve ter acesso direto à GU, uma vez que essa opção está disponível em outras línguas naturais. 
Resultados como esses nos levam ponderar sobre a importância da natureza do input linguístico na aquisição de L2. Compreendemos que a GU disponibiliza possibilidades para a fixação de parâmetros na aquisição das línguas, e o adquirente de L2 tem de fazer considerações antes da marcação de um parâmetro na nova língua (BALDĖ, 2011). É preciso considerar que o input tem papel fundamental para que essa escolha ocorra. No caso do surdo, que adquire o português (L2) na modalidade escrita, é preciso considerar a natureza desse input, que será fornecido por imersão em ambientes diversos, destacando-se, naturalmente, a escola, onde o ensino da língua é planejado e formal. No caso da aquisição do determinante, em particular o artigo (definido), Baldé (2011, p. 9) diz que "[e]xiste um grupo de propriedades sintáticas, morfológicas, semânticas e pragmáticas que o sujeito tem de descobrir através da exposição à língua.” De acordo com lonin (2003), apud Baldé (2011), o indivíduo precisa fazer uma generalização tomando por base as informações do input linguístico. Daí o interesse desse estudo também em sinalizar a importância da natureza e do papel do input fornecido ao aprendiz surdo na aquisição de português como segunda língua. Essa questão desafia os pesquisadores, na identificação das fases da interlíngua e das estruturas envolvidas, assim como os educadores, na formulação de métodos e técnicas cientificamente respaldados a fim de cumprir as exigências acadêmicas da educação bilíngue e garantir os resultados esperados.

\section{REFERÊNCIAS}

ABNEY, Steven. The English noun phrase in its sentential aspect. Doctoral Dissertation, MIT, Cambridge, 1987.

BALDĖ, Nailia Rafikovna. Aquisição do artigo em português $L 2$ por falantes de L1 russo. Dissertação de mestrado pela Universidade de Lisboa. Lisboa, 2011.

BENVENISTE, Émile. Problemas de linguística geral v. 1. $4^{\mathrm{a}}$ ed. Tradução de Maria da Glória Novak e Maria Luisa Néri. Campinas: Pontes, 1976.

BRITO, Maria Ana. Os possessivos em português numa perspectiva de Sintaxe Comparada. Revista da Faculdade de Letras - 'Línguas e Literaturas' XX: 495- 522, 2003.

CAPOVILLA, Fernando César; RAPHAEL, Walkiria Duarte; MAURICIO, Aline Cristina. Dicionário enciclopédico ilustrado trilíngue: novo Deit-Libras Língua de Sinais Brasileira. Vol. 1: sinais de A a H. São Paulo: Inep - CNPa CAPES, Edusp, 2013.

CARVALHO, Danniel. A estrutura interna dos pronomes pessoais em português brasileiro. Dissertação para obtenção do título de Mestre em Linguística, Universidade Federal de Alagoas - UFAL. Maceió, 2008.

CARVALHO, Joana. A posição sintática do demonstrativo em português europeu. eLing Up -Centro de Linguística da Universidade do Porto, Volume 3, Número 1, 2011.

CHOMSKY, Noam. Aspects of the Theory of Syntax. MIT Press, 1965

CHOMSKY, Noam. Knowledge of language: its nature, origin and use. Praeger: New York, 1986.

CHOMSKY, Noam. O programa minimalista. Lisboa: Caminho, Tradução Eduardo P. Raposo. Lisboa, 1999. 
CHOMSKY, Noam. Problemas do conhecimento e da liberdade. Tradução Paulo G. Domenech Oneto. Original: Problems of knowledge and freedom. Copyright 1971. Editora Record. Rio de Janeiro, 2008.

ELLIS, Rod. Second language acquisition. Oxford: Oxford University Press, 1997.

FERREIRA-BRITO, Lucinda. Por uma gramática das línguas de sinais. Editora Tempo Brasileiro/UFRJ, Rio de Janeiro, 1995.

LIMA-SALLES, Heloisa Maria; SALLES, Paulo Sérgio Bretas; CHAN-VIANNA, Adriana Cristina. Formulação de interferências e propriedades de interlíngua dos surdos na aquisição do português (escrito). In: Bilinguismo dos surdos: questões linguísticas e educacionais. Cânone Editorial. Goiânia, 2007.

MACEDO-COSTA, Tatiane. Determinantes definidos: um estudo sobre a estrutura dos DPs na história do português. Tese para a obtenção do título de doutor pela Universidade Estadual de Campinas. Campinas, 2016.

PAIVA, Vera Lúcia Menezes de Oliveira. O. Aquisição de segunda língua. Editora Parábola, São Paulo, 2014.

PRADO, Lizandra Caires. Sintaxe dos determinantes na língua brasileira de sinais e aspectos de sua aquisição. Dissertação para obtenção do título de Mestre pela Universidade Estadual do Sudoeste da Bahia UESB. 2014.

PRADO, Lizandra Caires; LESSA-DE-OLIVEIRA, Adriana Stella Cardoso. Dêixis em elementos constitutivos da modalidade falada de línguas de sinais. Revista Virtual de Estudos da Linguagem, v. 10, p. 38-57, 2012.

QUADRO EUROPEU COMUM DE REFERÊNCIA PARA AS LÍNGUAS - Aprendizagem, ensino, avaliação Conselho da Europa, 2001. In: http://area.dge.mec.pt/gramatica/Quadro_Europeu_total.pdf Acesso em: abril.2020.

QUADROS, Ronice Muller. Educação de surdos: a aquisição da linguagem. Artmed Editora AS, Porto Alegre, RS, 1997.

QUADROS, Ronice Muller; CRUZ, Carina Rabello. Língua de sinais: instrumentos de avaliação. Artmed Editora AS, Porto Alegre, RS, 2011.

SALLES, Heloisa Maria; FAULSTICH, Enilde; CARVALHO, Orlene Saboia; RAMOS, Ana. Adelina. Ensino de língua portuguesa para surdos: caminhos para a prática pedagógica. Volume 1. Brasília: MEC, SEESP, 2007.

SILVA, Rosana Cipriano; KELMAN, Celeste; SALLES, Heloisa Maria. Formação de professores na educação de surdos. In: SALLES, P. S. B. A; GAUCHE, E. Educação científica, inclusão social e acessibilidade. Cânone Editorial. Goiânia, 2011.

WHITE, Lydia. Second Language Acquisition and Universal Grammar. Cambridge University Press, Cambridge, UK. 2003. 